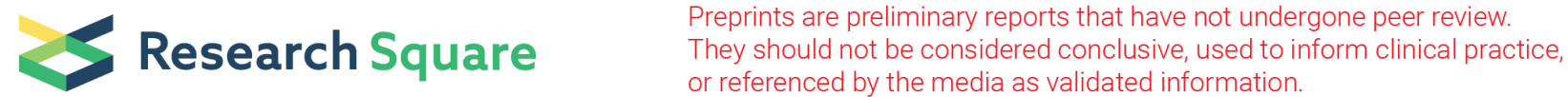

\section{Prognostic Significance of the Preoperative Prognostic Nutritional Index in Epithelial Ovarian Cancer Patients: A Systematic Review and Meta-analysis of Cohort Studies}

\author{
Ting-Ting Gong \\ Shengjing Hospital of China Medical University \\ Jia-Yu Zhang \\ Shengjing Hospital of China Medical University \\ Hui Sun \\ Shengjing Hospital of China Medical University \\ Qi-Jun Wu \\ Shengjing Hospital of China Medical University \\ Song Gao ( $\nabla$ gaos@sj-hospital.org ) \\ Shengjing Hospital of China Medical University
}

\section{Research article}

Keywords: Meta-analysis, nutritional index, Ovarian cancer, Preoperative, Survival, Systematic review

Posted Date: January 7th, 2020

DOI: https://doi.org/10.21203/rs.2.20066/v1

License: (c) (i) This work is licensed under a Creative Commons Attribution 4.0 International License. Read Full License 


\section{Abstract}

\section{Background}

The main aim of this study was to validate the potential association between the preoperative prognostic nutritional index (PNI) and survival of patients with ovarian cancer (OC).

\section{Methods}

We systematically searched multiple databases (PubMed, EMBASE, and Web of Science) for publications up to June 30, 2019 , to identify observational studies evaluating the PNI in relation to survival. Two reviewers independently extracted data and assessed the quality of each study using the Newcastle-Ottawa Scale (NOS). Summary hazard ratios (HR) and 95\% confidence intervals $(\mathrm{Cl})$ were calculated with the aid of a random-effects model. The potential for publication bias was explored using Funnel plots as well as Begg's and Egger's tests.

\section{Results}

Among the 15,000 studies selected for selection, 5 retrospective cohort studies (4 from China and one from Japan) comprising 1964 OC patients met the inclusion criteria. All studies were graded as 'low risk of bias' according to NOS. A low preoperative $\mathrm{PNI}$ was associated with poor overall survival $(\mathrm{HR}=1.69,95 \% \mathrm{Cl}=1.16-2.46 ; 12=83.8 \%)$ and progression-free survival $(\mathrm{HR}=1.86,95 \% \mathrm{Cl}=1.39-2.51 ; 12=29.7 \%)$ of OC patients. No significant publication bias was detected.

\section{Conclusions}

Collective data from the present systematic review and meta-analysis suggest that a low preoperative PNI is associated with poor survival in OC. Further prospective studies are required to confirm these findings.

\section{Background}

Although the global burden of ovarian cancer (OC) decreased between 1990 and 2017 [1], this disease remains the most lethal gynecological cancer type worldwide [2]. An estimated 295,414 new cases and 184,799 deaths from OC were recorded in 2018 [2]. Due to late-stage diagnosis and resistance to chemotherapy, survival rates of OC are particularly poor. Almost $80 \%$ OC patients display tumor progression and relapse after first-line chemotherapy within 1-2 years, leading to $>50 \%$ mortality within a 5-year period $[3,4]$.

Onodera et al. [5] first introduced the prognostic nutritional index (PNI) in 1984 calculated based on the serum albumin concentration and peripheral blood lymphocyte count to assess the nutritional and immunological status of patients subjected to gastrointestinal surgery. During the past few decades, numerous studies have investigated the potential utility of the PNI as a novel predictive and prognostic marker in various malignancies, including pancreatic cancer, gastric cancer, lung cancer, and colorectal cancer [6-9]. However, evidence of the significance of the PNI in OC is controversial. A retrospective study by Feng et al. [10] on 875 OC patients revealed null results between preoperative PNI and overall survival (OS) of OC, in contrast to other studies that showed a significant association [11-13]. Interestingly, a systematic review and meta-analysis in 2019 by Wang et al. [14] showed significant association of the PNI with the prognosis of patients with gynecological cancer. However, several limitations of this earlier study should be addressed. First, the reference group for comparison was set as OC patients with a low PNI as proposed by Feng et al [10]. Conversely, other included studies [11-13] set the reference comparison group as OC patients with a high PNI. These mixed risk estimates were summarized directly instead of recalculating on the basis of comparable reference groups. Secondly, Wang et al. [14] provided PNI calculations of all included studies in their meta-analysis. However, one of the included studies by Yim and co-workers [15] focused on exposure according to the nutrition risk index ((15.19* serum albumin, $\mathrm{g} / \mathrm{L})+\left(41.7^{*}\right.$ current/usual body weight, $\left.\left.\mathrm{kg}\right)\right)$, which is distinct from the PNI. In view of the different definitions of exposure, this study should have been excluded. Furthermore, 
after publication of the above systematic review [14], a novel study conducted by Komura et al.[16] reported that decreased $\mathrm{PNI}$ is an independent prognostic predictor of recurrence and short survival in advanced-stage OC patients.

To address the discrepancies and elucidate the relationship between the PNI and prognosis in OC, we performed a further systematic review and meta-analysis based on comprehensive and updated evidence from published observational studies.

\section{Methods}

\section{Data sources and searches}

The results of this study are reported according to Preferred Reporting Items for Systematic Reviews and Meta-Analyses (PRISMA) guidelines [17]. We systematically searched PubMed, Embase and Web of Science databases for available literature up to June 30,2019, without language restrictions. References were assessed for additional articles overlooked during the primary search $[18,19]$. We employed a search strategy with the aid of a biomedical information specialist. The following search keywords and terms were used and appropriately translated for the other databases: ((nutritional index) or (albumin) or (lymphocyte)) and ((ovary) or (ovarian)) and ((neoplasms) or (tumour) or (tumor) or (cancer) or (carcinoma)). Searches were undertaken and two reviewers (T-TG and HS) independently assessed the literature for study inclusion.

\section{Study selection}

Articles for further assessment were independently selected by two reviewers (T-TG and Q-JW). Articles were included or excluded based on predefined selection criteria before beginning our search. Decisions were based on consensus. Authors were contacted via email in cases where clarification was required. Duplicate reports were removed both automatically and manually using a reference management library. Studies were eligible if they (1) were cohort or randomized controlled trials, (2) defined exposure as a preoperative PNI of $10 \times$ serum albumin value $(\mathrm{g} / \mathrm{dl})+0.005 \times$ lymphocyte count $\left(\mathrm{per}_{\mathrm{mm}} \mathrm{m}^{3}\right)$ in peripheral blood for OC patients, (3) defined outcome as progression-free survival (PFS) or OS of OC, (4) provided appropriate risk estimates (i.e., relative risk or hazard ratio (HR)) of the association between preoperative PNI and survival of OC (if multiple estimates were available, we extracted the estimate that adjusted for the most covariates). Studies were excluded if they (1) were published as letters, editorials, reviews, notes, commentaries, meeting abstracts, case reports, casecontrol analyses and conducted in animals and (2) reported risk estimates without $95 \%$ confidence intervals $(\mathrm{Cl})$.

\section{Data abstraction and quality assessment}

Data were independently extracted in duplicate by two reviewers using standardized forms (T-TG and J-YZ). Disagreements were resolved by consensus. From each study, the following information was extracted: first author name, publication year, country, patient characteristics, category of exposures and outcomes, and adjustment for confounders.

Quality assessment of the included studies was performed using the Newcastle-Ottawa Scale for observational studies [20] that consists of eight items grouped into three domains (selection, comparability, and outcome). A maximum of nine stars was awarded to any individual study. Studies that achieved a full rating in at least two categories of the three assessments were considered to have low risk of bias [21, 22].

\section{Statistical analysis}

For one study that did not use OC patients with high preoperative PNI as a reference group[10], the effective count method proposed by Hamling et al. [23] was applied to recalculate HR and 95\% Cl. Risk estimates were summarized using a random-effects model, since differences in populations and settings between studies could not easily justify a common effect size. Potential heterogeneity in results across studies was examined using $R$ statistics [24]. Cut-off points $\leq 50 \%, 51-$ $75 \%$ and ${ }^{3} 76 \%$ were used to indicate low, moderate and substantial heterogeneity, respectively. The potential for small-study effects, such as publication bias, was assessed using Funnel plot, Egger's linear regression [25] and Begg's rank correlation 
[26] methods. A probability $(P)$ value $<0.05$ for the two tests was considered representative of significant publication bias. All statistical analyses were performed using Stata 12.0 software (Stata LLC, College Station, TX, USA).

\section{Results}

\section{Selection process}

Our search yielded 15,000 articles. After removal of duplicates, the titles and abstracts of 14,471 articles were screened for further evaluation. A total of 11 articles were selected for full review, as shown in Figure 1. Six articles were excluded for various reasons, leading to the final inclusion of five articles for study $[10-13,16]$.

\section{Study characteristics}

Table 1 summarizes the characteristics of the five included studies. In total, 1964 OC patients were included from four studies conducted in China [10-13] and one in Japan [16]. Four and three studies focused on the association between PNI and OS and progression-free survival (PFS), respectively. The majority of studies were adjusted for age/age at diagnosis $(n=4)$, FIGO stage $(n=3)$, residual disease $(n=3)$, and histology $(n=3)$ and a few adjusted for body mass index $(n=2)$, grade $(n=2)$, and chemotherapy $(n=2)$. None of the included studies were adjusted for race or comorbidity (Table 2$)$.

\section{Quality assessment}

Table 3 provides details of the study quality assessment reflected by NOS scores. All the included studies had low risk of bias. Notably, in our classification of comparability, two included studies $[12,16]$ were not assigned two scores since they had been adjusted for less than two important confounders.

\section{PNI and OC survival}

Study-specific and summarized HR and $95 \% \mathrm{Cl}$ of PFS and OS for high versus low PNI are presented in Figure 2. Overall, compared to $\mathrm{OC}$ patients with a high preoperative $\mathrm{PNI}$, those with a low preoperative PNI showed significantly poorer PFS $(\mathrm{HR}=1.86,95 \% \mathrm{Cl}=1.39-2.51 ; P=29.7 \%)$ and $\mathrm{OS}(\mathrm{HR}=1.69,95 \% \mathrm{Cl}=1.16-2.46 ; P=83.8 \%)$. No significant publication bias was detected ( $P$ for Begg's test $=0.805, P$ for Egger's test $=0.364$ ).

\section{Discussion}

Our meta-analysis of 5 retrospective cohorts involving a total of 1964 OC patients showed $86 \%$ and $69 \%$ poorer PFS and OS, respectively, in the patient group with low preoperative PNI relative to the high preoperative PNI group.

Compared to the previously documented meta-analysis by Wang et al. [14], our study has several strengths. Firstly, we unified the reference group as OC patients with a high preoperative PNI. Secondly, all included studies had a standard definition of exposure and outcome. Furthermore, although our study has not been registered, experiments were performed in compliance with PRISMA guidelines [17]. However, a number of limitations exist that should also be acknowledged. Firstly, a low preoperative PNI is typically associated with OC patients with more comorbidities, higher cancer burden (e.g., advanced FIGO stage, larger residual tumor mass, positive ascites) and chemoresistance [10-13, 16]. Many, but not all the earlier studies were adjusted for these potential confounding factors, although not all potential confounders were adjusted for in each included study. Therefore, we could not rule out the possibility of unmeasured or residual confounding in the present meta-analysis. Additionally, comparability (control for important or additional factors) is the only problem of quality assessment, similar to the above issue. Secondly, since preoperative PNI data were collected through medical records from each hospital, our study could not prone to measurement errors. However, the cut-off value of preoperative PNI was defined based on the maximum Youden index in the receiver operating characteristics curve for survival of OC, which was heterogeneous among the included studies $[10-13,16]$. Thirdly, due to the limited number of available studies, we were 
restricted in terms of performing subgroup and sensitivity analyses to explore the source of heterogeneity. Furthermore, all included studies were a retrospective cohort design, which might be attributed to potential recall bias. Although high heterogeneity was only observed in analysis of OS, further studies are warranted to establish the association between preoperative PNI and survival of patients with OC. Finally, publication bias is a major problem in meta-analyses. However, we observed no evidence of bias with Egger's test, Begg's test and Funnel plot analysis.

Although we observed a significant association between preoperative PNI and OC survival, the precise biological mechanisms underlying this link are currently unknown. Several potential mechanisms, including malnutrition and inflammation, may contribute to the issue. Malnutrition accounts for $20 \%$ of all cancer-associated deaths [27]. Owing to the metabolic effects of cancer mass, malignant ascites and small bowel obstruction, patients with OC are more likely to present with malnutrition and cachexia [28]. A recent study showed that patients with OC are at a 19-fold greater risk of malnourishment than those with benign conditions [29]. Malnutrition as well as compromised immunological status are believed to be the main contributory factors to increased risk of postoperative complications and tumor spread [30]. On the other hand, as components of the PNI, both albumin and lymphocyte count are closely related to inflammatory responses in cancer patients [13], which are independent predictors of long-term outcomes in OC. Additionally, lymphocytes are reported to play a major role in immune responses through mediating immunologic damage caused by various cancer types [31]. Therefore, the PNI may be involved in the systemic inflammatory response and play an indispensable role in cancer growth and metastasis [32-34].

\section{Conclusions}

In summary, our systematic review and meta-analysis provides further evidence that a low preoperative PNI is associated with poorer PFS and OS of OC. Future studies should focus on confirming this finding and exploring further results based on histological type and FIGO stage.

\section{Declarations}

Ethics approval and consent to participate: Not applicable

Consent for publication: Not applicable

Availability of data and materials: Not applicable

Competing interests: The authors declare that the research was conducted in the absence of any commercial or financial relationships that could be construed as a potential conflict of interest.

\section{Funding:}

This study was supported by grants from the Natural Science Foundation of China (No. 81602918 to Q-JW), the China Postdoctoral Science Foundation Funded Project (No. 2018M641752 to Q-JW), the Doctoral Start-up Foundation of Liaoning Province (No. 201501007 to Q-JW), the Younger research fund of Shengjing Hospital (Grant 2014sj09 to Q-JW), and the Campus Research Fund of China Medical University (No. YQ20170002 to Q-JW). We thank Qi-Jun Wu for assistance in typing the various drafts of the paper and obtaining the relevant literature.

\section{Authors' contributions:}

T-TG and SG designed the research; T-TG, J-YZ, HS, and SG conducted the research; T-TG, Q-JW, and SG analyzed data; T-TG, Q-JW, and SG wrote the draft manuscript. All the authors read, reviewed, and approved the final manuscript. Q-JW and SG had primary responsibility for all the final content. All authors have read and approved the manuscript. 


\section{Abbreviations}

Cl: confidence interval; FIGO: International Federation of Gynecology and Obstetrics; HR: hazard ratio; NOS: NewcastleOttawa Scale; OC: ovarian cancer; OS: overall survival; PFS: progression-free survival; PNI: prognostic nutritional index; PRISMA: Preferred Reporting Items for Systematic Reviews and Meta-Analyses.

\section{References}

1. Fitzmaurice C, Akinyemiju TF, Al LF, Alam T, Alizadeh-Navaei R, Allen C, et al. Global, Regional, and National Cancer Incidence, Mortality, Years of Life Lost, Years Lived With Disability, and Disability-Adjusted Life-Years for 29 Cancer Groups, 1990 to 2016: A Systematic Analysis for the Global Burden of Disease Study. JAMA ONCOL 2018,4:1553-68.

2. Bray F, Ferlay J, Soerjomataram I, Siegel RL, Torre LA, Jemal A. Global cancer statistics 2018: GLOBOCAN estimates of incidence and mortality worldwide for 36 cancers in 185 countries. CA Cancer J Clin 2018,68:394-424.

3. Torre LA, Trabert B, DeSantis CE, Miller KD, Samimi G, Runowicz CD, et al. Ovarian cancer statistics, 2018. CA Cancer J Clin 2018,68:284-96.

4. Jayson GC, Kohn EC, Kitchener HC, Ledermann JA. Ovarian cancer. LANCET 2014,384:1376-88.

5. Onodera T, Goseki N, Kosaki G. [Prognostic nutritional index in gastrointestinal surgery of malnourished cancer patients]. Nihon Geka Gakkai Zasshi 1984,85:1001-5.

6. Li S, Tian G, Chen Z, Zhuang Y, Li G. Prognostic Role of the Prognostic Nutritional Index in Pancreatic Cancer: A Metaanalysis. NUTR CANCER 2019,71:207-13.

7. Li D, Yuan X, Liu J, Li C, Li W. Prognostic value of prognostic nutritional index in lung cancer: a meta-analysis. J THORAC DIS 2018,10:5298-307.

8. Yang Y, Gao P, Chen X, Song Y, Shi J, Zhao J, et al. Prognostic significance of preoperative prognostic nutritional index in colorectal cancer: results from a retrospective cohort study and a meta-analysis. Oncotarget 2016,7:58543-52.

9. Yang Y, Gao P, Song Y, Sun J, Chen X, Zhao J, et al. The prognostic nutritional index is a predictive indicator of prognosis and postoperative complications in gastric cancer: A meta-analysis. Eur J Surg Oncol 2016,42:1176-82.

10. Feng Z, Wen H, Ju X, Bi R, Chen X, Yang W, et al. The preoperative prognostic nutritional index is a predictive and prognostic factor of high-grade serous ovarian cancer. BMC CANCER 2018,18:883.

11. Zhang W, Ye B, Liang W, Ren Y. Preoperative prognostic nutritional index is a powerful predictor of prognosis in patients with stage III ovarian cancer. Sci Rep 2017,7:9548.

12. Liu Y, Chen S, Zheng C, Ding M, Zhang L, Wang L, et al. The prognostic value of the preoperative c-reactive protein/albumin ratio in ovarian cancer. BMC CANCER 2017,17:285.

13. Miao Y, Li S, Yan Q, Li B, Feng Y. Prognostic Significance of Preoperative Prognostic Nutritional Index in Epithelial Ovarian Cancer Patients Treated with Platinum-Based Chemotherapy. ONCOL RES TREAT 2016,39:712-9.

14. Wang $X$, Wang $Y$. The prognostic nutritional index is prognostic factor of gynecological cancer: A systematic review and meta-analysis. INT J SURG 2019,67:79-86.

15. Yim GW, Eoh KJ, Kim SW, Nam EJ, Kim YT. Malnutrition Identified by the Nutritional Risk Index and Poor Prognosis in Advanced Epithelial Ovarian Carcinoma. NUTR CANCER 2016,68:772-9.

16. Komura N, Mabuchi S, Yokoi E, Shimura K, Kawano M, Matsumoto Y, et al. Prognostic significance of the pretreatment prognostic nutritional index in patients with epithelial ovarian cancer. Oncotarget 2019,10:3605-13.

17. Liberati A, Altman DG, Tetzlaff J, Mulrow C, Gotzsche PC, loannidis JP, et al. The PRISMA statement for reporting systematic reviews and meta-analyses of studies that evaluate healthcare interventions: explanation and elaboration. BMJ 2009,339:b2700.

18. Wu QJ, Wu L, Zheng LQ, Xu X, Ji C, Gong TT. Consumption of fruit and vegetables reduces risk of pancreatic cancer: evidence from epidemiological studies. EUR J CANCER PREV 2016,25:196-205. 
19. Gong TT, Wu QJ, Wang YL, Ma XX. Circulating adiponectin, leptin and adiponectin-leptin ratio and endometrial cancer risk: Evidence from a meta-analysis of epidemiologic studies. INT J CANCER 2015,137:1967-78.

20. Wells GA SBOD. The Newcastle-Ottawa Scale (NOS) for assessing the quality of nonrandomised studies in metaanalyses. Available at http://www.ohri.ca/programs/clinical_epidemiological/oxford.asp (last accessed 6 February 2018). 2018.

21. Odutayo A, Wong CX, Hsiao AJ, Hopewell S, Altman DG, Emdin CA. Atrial fibrillation and risks of cardiovascular disease, renal disease, and death: systematic review and meta-analysis. BMJ 2016,354:i4482.

22. Gao SY, Wu QJ, Sun C, Zhang TN, Shen ZQ, Liu CX, et al. Selective serotonin reuptake inhibitor use during early pregnancy and congenital malformations: a systematic review and meta-analysis of cohort studies of more than 9 million births. BMC MED 2018,16:205.

23. Hamling J, Lee $P$, Weitkunat R, Ambuhl M. Facilitating meta-analyses by deriving relative effect and precision estimates for alternative comparisons from a set of estimates presented by exposure level or disease category. STAT MED 2008,27:954-70.

24. Higgins JP, Thompson SG. Quantifying heterogeneity in a meta-analysis. STAT MED 2002,21:1539-58.

25. Egger M, Davey SG, Schneider M, Minder C. Bias in meta-analysis detected by a simple, graphical test. BMJ 1997,315:629-34.

26. Begg CB, Mazumdar M. Operating characteristics of a rank correlation test for publication bias. BIOMETRICS 1994,50:1088-101.

27. Ottery FD. Cancer cachexia: prevention, early diagnosis, and management. Cancer Pract 1994,2:123-31.

28. Laky B, Janda M, Cleghorn G, Obermair A. Comparison of different nutritional assessments and body-composition measurements in detecting malnutrition among gynecologic cancer patients. AM J CLIN NUTR 2008,87:1678-85.

29. Alvaro SE, Garrido SM, Rey FL, Villatoro RR, Rueda DA, Abiles J. Nutritional risk and malnutrition rates at diagnosis of cancer in patients treated in outpatient settings: Early intervention protocol. NUTRITION 2019,57:148-53.

30. Migita K, Takayama T, Saeki K, Matsumoto S, Wakatsuki K, Enomoto K, et al. The prognostic nutritional index predicts long-term outcomes of gastric cancer patients independent of tumor stage. ANN SURG ONCOL 2013,20:2647-54.

31. Liu B, Huang Y, Sun Y, Zhang J, Yao Y, Shen Z, et al. Prognostic value of inflammation-based scores in patients with osteosarcoma. Sci Rep 2016,6:39862.

32. Douglas E, McMillan DC. Towards a simple objective framework for the investigation and treatment of cancer cachexia: the Glasgow Prognostic Score. CANCER TREAT REV 2014,40:685-91.

33. Choi KW, Hong SW, Chang YG, Lee WY, Lee B, Paik IW, et al. Inflammation-based score (Glasgow prognostic score) as an independent prognostic factor in colorectal cancer patients. ANN SURG TREAT RES 2014,86:309-13.

34. de Martino M, Pantuck AJ, Hofbauer S, Waldert M, Shariat SF, Belldegrun AS, et al. Prognostic impact of preoperative neutrophil-to-lymphocyte ratio in localized nonclear cell renal cell carcinoma. J Urol 2013,190:1999-2004.

\section{Tables}

Table 1. Characteristics of the included studies 


\begin{tabular}{|c|c|c|c|c|c|c|c|}
\hline $\begin{array}{l}\text { First Author, } \\
\text { (Ref), Year }\end{array}$ & Country & Study design & $\begin{array}{l}\text { No. of } \\
\text { cases }\end{array}$ & Outcome & $\begin{array}{l}\text { No. of } \\
\text { events }\end{array}$ & $\begin{array}{c}\text { Patient } \\
\text { stage/grade }\end{array}$ & $\begin{array}{l}\text { Exposure } \\
\text { category }\end{array}$ \\
\hline $\begin{array}{ll}\text { Komura } & \text { et } \\
\text { al [16], } 2019 & \end{array}$ & Japan & $\begin{array}{l}\text { Retrospective } \\
\text { cohort }\end{array}$ & 308 & $\begin{array}{l}\text { Progression-free } \\
\text { survival } \\
\text { Disease-specific } \\
\text { survival }\end{array}$ & N/A & All & 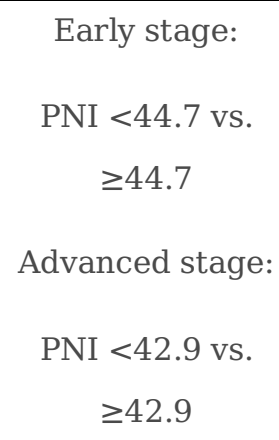 \\
\hline $\begin{array}{l}\text { Feng et al [10], } \\
2018\end{array}$ & China & $\begin{array}{c}\text { Retrospective } \\
\text { cohort }\end{array}$ & 875 & Overall survival & 457 & High grade & $\begin{aligned} \mathrm{PNI} & \geq 45.45 \text { vs. } \\
& <45.45\end{aligned}$ \\
\hline $\begin{array}{l}\text { Zhang et al [11], } \\
2017\end{array}$ & China & $\begin{array}{c}\text { Retrospective } \\
\text { cohort }\end{array}$ & 237 & $\begin{array}{l}\text { Progression-free } \\
\text { survival } \\
\text { Overall survival }\end{array}$ & N/A & Stage III & $\begin{aligned} \text { PNI } & <47.2 \text { vs. } \\
& \geq 47.2\end{aligned}$ \\
\hline $\begin{array}{l}\text { Liu et al [12], } \\
2017\end{array}$ & China & $\begin{array}{c}\text { Retrospective } \\
\text { cohort }\end{array}$ & 200 & Overall survival & 103 & All & PNI $<48$ vs. $\geq 48$ \\
\hline $\begin{array}{l}\text { Miao et al [13], } \\
2016\end{array}$ & China & $\begin{array}{c}\text { Retrospective } \\
\text { cohort }\end{array}$ & 344 & $\begin{array}{l}\text { Progression-free } \\
\text { survival } \\
\text { Overall survival }\end{array}$ & $\mathrm{N} / \mathrm{A}$ & All & PNI $<45$ vs. $\geq 45$ \\
\hline
\end{tabular}

N/A, not available; PNI, prognostic nutritional index

Table 2. Adjustment of potential confounders in the included studies 


\begin{tabular}{|c|c|c|c|c|c|c|c|c|c|}
\hline \multirow{2}{*}{$\begin{array}{l}\text { First } \\
\text { Author, } \\
\text { Year }\end{array}$} & \multicolumn{9}{|c|}{ Adjustment for potential confounders in the primary analysis } \\
\hline & $\begin{array}{l}\text { Age/Age at } \\
\text { diagnosis }\end{array}$ & Race & BMI & $\begin{array}{l}\text { FIGO } \\
\text { stage }\end{array}$ & Grade & Histology & Comorbidity & $\begin{array}{l}\text { Residual } \\
\text { disease }\end{array}$ & Chemotherapy \\
\hline $\begin{array}{l}\text { Komura et al [16], } \\
2019\end{array}$ & Yes & No & No & No & No & Yes & No & No & No \\
\hline $\begin{array}{l}\text { Feng et al [10], } \\
2018\end{array}$ & Yes & No & No & Yes & No & No & No & Yes & Yes \\
\hline $\begin{array}{l}\text { Zhang et al [11], } \\
2017\end{array}$ & Yes & No & Yes & Yes & Yes & Yes & No & Yes & Yes \\
\hline $\begin{array}{l}\text { Liu et al [12], } \\
2017\end{array}$ & No & No & No & No & No & No & No & No & No \\
\hline $\begin{array}{l}\text { Miao et al [13], } \\
2016\end{array}$ & Yes & No & Yes & Yes & Yes & Yes & No & Yes & No \\
\hline
\end{tabular}

BMI, body mass index; FIGO, International Federation of Gynecology and Obstetrics

Table 3. Methodological quality of the included studies 


\begin{tabular}{|c|c|c|c|c|c|c|c|c|}
\hline & & Selection & & & Comparability & & Outcome & \\
\hline $\begin{array}{l}\text { First } \\
\text { author } \\
\text { (Ref), } \\
\text { year }\end{array}$ & $\begin{array}{l}\text { Representativeness of } \\
\text { the exposed cohort }\end{array}$ & $\begin{array}{l}\text { Selection } \\
\text { of the } \\
\text { unexposed } \\
\text { cohort }\end{array}$ & $\begin{array}{c}\text { Ascertainment } \\
\text { of exposure }\end{array}$ & $\begin{array}{c}\text { Outcome } \\
\text { of } \\
\text { interest } \\
\text { not } \\
\text { present } \\
\text { at start } \\
\text { of study }\end{array}$ & $\begin{array}{c}\text { Control for } \\
\text { important factor } \\
\text { or additional } \\
\text { factor }{ }^{\dagger}\end{array}$ & $\begin{array}{l}\text { Assessment } \\
\text { of outcome }\end{array}$ & $\begin{array}{l}\text { Follow- } \\
\text { up long } \\
\text { enough } \\
\text { for } \\
\text { outcomes } \\
\text { to occur }\end{array}$ & $\begin{array}{c}\text { Adequacy } \\
\text { of follow- } \\
\text { up of } \\
\text { cohorts }\end{array}$ \\
\hline $\begin{array}{l}\text { Komura } \\
\text { et } \\
\text { al [16], } \\
2019\end{array}$ & $*$ & $*$ & $*$ & $*$ & $*$ & $*$ & $*$ & $*$ \\
\hline $\begin{array}{l}\text { Feng et } \\
\text { al [10], } \\
2018\end{array}$ & $*$ & $*$ & $*$ & $*$ & $* *$ & $*$ & $*$ & $*$ \\
\hline $\begin{array}{l}\text { Zhang } \\
\text { et } \\
\text { al [11], } \\
2017\end{array}$ & $*$ & $*$ & $*$ & $*$ & $* *$ & $*$ & $*$ & $*$ \\
\hline $\begin{array}{l}\text { Liu et } \\
\text { al [12], } \\
2017\end{array}$ & $*$ & $*$ & $*$ & $*$ & - & $*$ & $*$ & $*$ \\
\hline $\begin{array}{l}\text { Miao et } \\
\text { al [13], } \\
2016\end{array}$ & $*$ & $*$ & $*$ & $*$ & $* *$ & $*$ & $*$ & $*$ \\
\hline
\end{tabular}

A study could be awarded a maximum of one star for each item, except for 'Control for important factor or additional factor'. Definition/explanation of each column of the Newcastle-Ottawa Scale is available from (http://www.ohri.ca/programs/clinical_epidemiology/oxford.asp).

† A maximum of two stars could be awarded for this item. Studies that controlled for age at diagnosis and International Federation of Gynecology and Obstetrics (FIGO) stage received one star whereas those that controlled for other important confounders, such as comorbidity, received an additional star.

‡ A cohort study with median follow-up time $\geq 24$ months was assigned one star.

$\S$ A cohort study with follow-up rates $>75 \%$ was assigned one star.

\section{Figures}




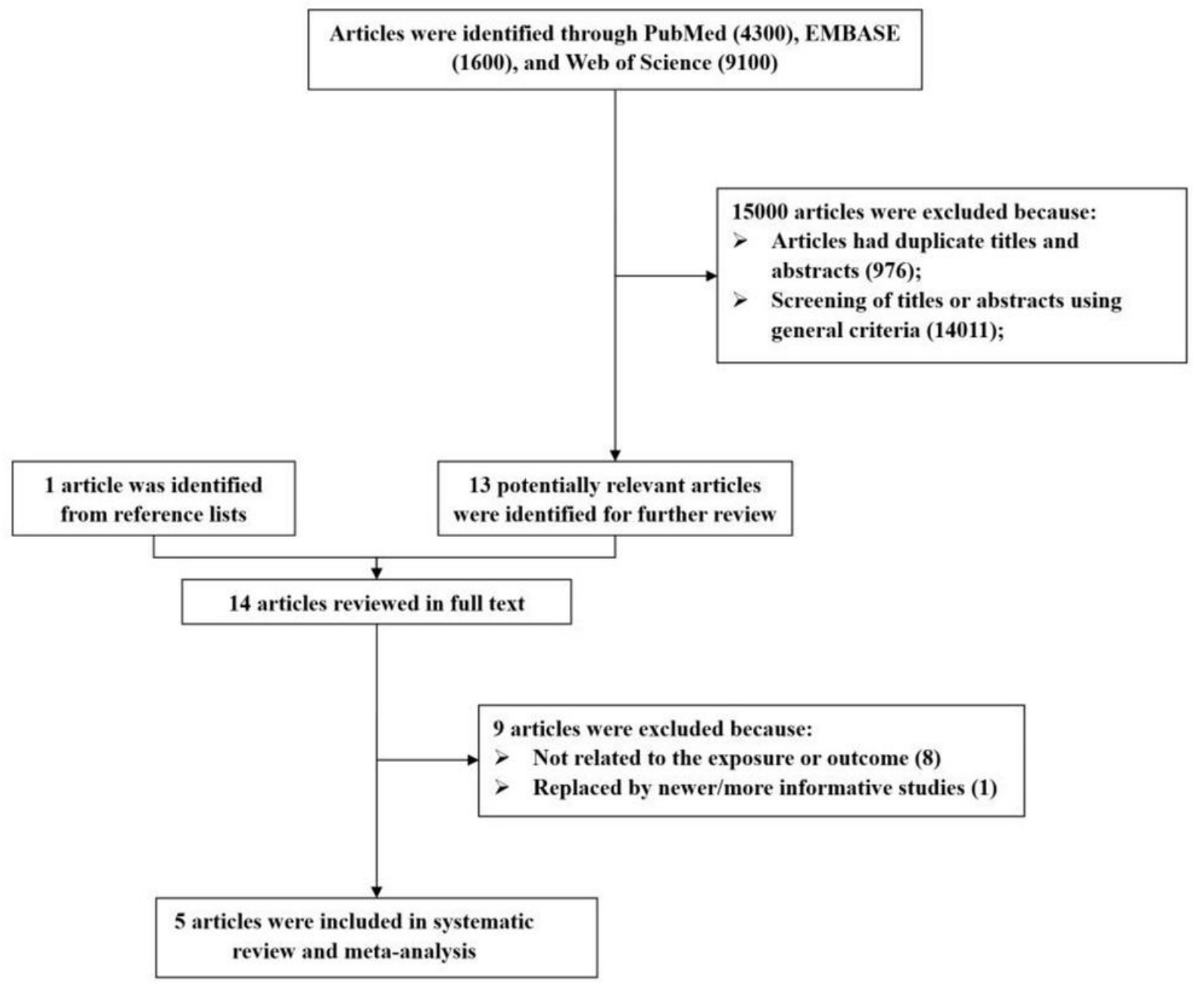

Figure 1

Screening and selection of studies evaluating the relationship between the prognostic nutritional index and ovarian cancer survival. 


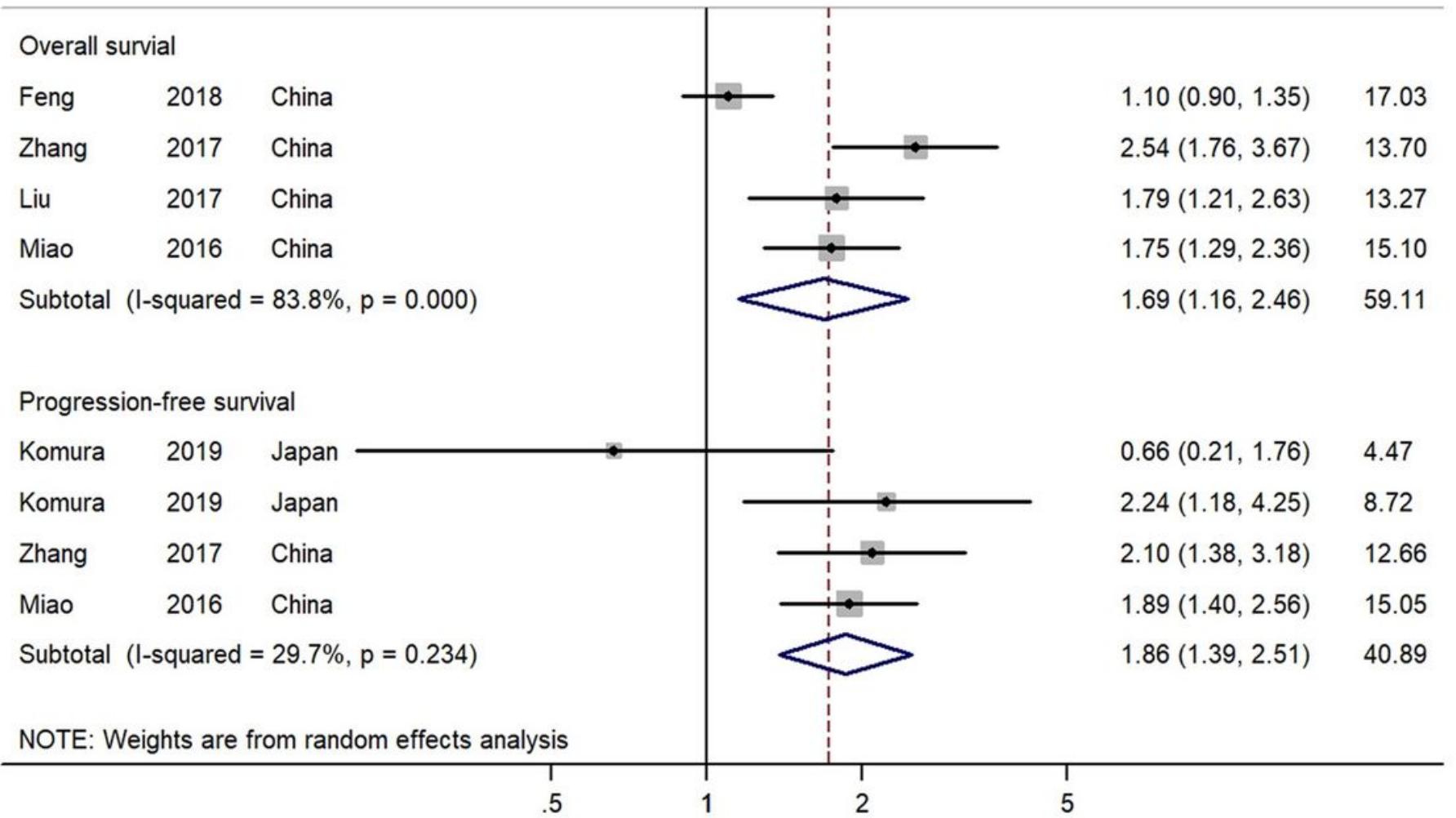

\section{Figure 2}

Forest plot (random-effects model) of the prognostic nutritional index and progression-free and overall survival of ovarian cancer patients (low vs. high). The squares indicate study-specific hazard ratio (the size of the square reflects study-specific statistical weight). Horizontal lines indicate $95 \% \mathrm{Cl}$ and the diamond signifies the summary hazard ratio estimate with $95 \%$ $\mathrm{Cl}(\mathrm{Cl}$, confidence interval; HR, hazard ratio). 